\title{
PENGARUH MODEL PEMBELAJARAN CIRCUIT LEARNING BERBANTU MULTIMEDIA DAN MEDIA SEDERHANA TERHADAP KREATIVITAS SISWA
}

\author{
Meike Paranna $^{1^{*}}$, Gamaliel Septian Airlanda ${ }^{2}$ \\ ${ }^{1,2}$ Program Studi Pendidikan Guru Sekolah Dasar, Fakultas Keguruan dan Ilmu Pendidikan, \\ Universitas Kristen Satya Wacana, Indonesia
}

Korespondensi. *E-mail: 292016133@student.uksw.edu

\begin{abstract}
Abstrak
Tujuan penelitian ini adalah membuktikan perbedaan pengaruh penggunaan model pembelajaran Circuit Learning yang berbantu multimedia dan model pembelajaran circuit learning yang berbantu media sederhana terhadap kreativitas siswa. Jenis penelitian ini adalah eksperimen semu (Quasi Eksperiment Research)-non equivalent control group design. Teknik pengumpulan data melalui teknik observasi, tes dan dokumentasi. Hipotesis awal dalam penelitian ini adalah $\mathrm{H}_{\mathrm{o}}$ : Model pembelajaran circuit learning berbantu media sederhana lebih berpengaruh terhadap kreativitas siswa. Dari hasil uji t menggunakan Independent Sample ttest menunjukkan bahwa $t_{\text {hitung }}$ sebesar 2,393 dengan nilai signifikansi pada kolom $\operatorname{Sig}(2$-tailed) sebesar 0,020 . Berdasarkan hasil kriteria pengujian hipotesis, bahwa nilai signifikasinya menunjukkan $0,020<0,05$ sehingga $\mathrm{H}_{0}$ ditolak dan $\mathrm{H}_{\mathrm{a}}$ diterima, artinya model pembelajaran circuit learning berbantu multimedia lebih berpengaruh terhadap kreativitas siswa. Keberhasilan penelitian ini di dukung dengan adanya peningkatan hasil pretest ke postest dan juga rata-rata hasil penilaian kreativitas siswa yaitu membuat peta konsep/mind map yang lebih tinggi dibandingkan dengan menggunakan model pembelajaran circuit learning berbantu media sederhana.
\end{abstract}

Kata Kunci: Circuit Learning, Multimedia, Media sederhana

\section{THE EFFECT OF CIRCUIT LEARNING MODEL ASSITED BY MULTIMEDIA AND SIMPLE MEDIA ON THE STUDENT'S CREATIVITY}

\begin{abstract}
The purpose of this study is to prove the difference in the influence of the use of multimedia-assisted Circuit Learning models and simple media-assisted circuit learning models on students' creativity. This type of research is a quasiexperimental (Quasi Experiment Research) -non equivalent control group design. The data was collected by doing observations, tests, and documentation. The initial hypothesis in this study is $H_{0}$ : Simple media-assisted circuit learning model has more influental on students' creativity. From the results of the t-test using the Independent Sample t-test showed that the t count was 2.339 with a significance value in the Sig (2-tailed) column is 0.020. Based on the results of the hypothesis testing criteria, that the significance value showed $0.020<0.05$ so that $H_{0}$ is rejected and $H_{a}$ is accepted, meaning that the multimedia-assisted circuit learning model is more influential on students' creativity. The success of this study was supported by an increase in the results of the pre-test to the post-test and also the average results of the assessment of students' creativity, namely creating a concept map/mind map that are higher than using a simple mediaassisted circuit learning model.
\end{abstract}

Keywords:Circuit Learning, Multimedia, Simple Media

Copyright C2020, JRPD, ISSN 2615 - 1723 (Print), ISSN 2615 - 1766 (Online) 


\section{Jurnal Riset Pendidikan Dasar, 03 (1), April 2020 (57-63)}

Meike Paranna, Gamaliel Septian Airlanda

\section{PENDAHULUAN}

IPA di sekolah dasar bertujuan agar dapat menumbuhkan sikap ilmiah siswa, sikap ilmiah yaitu keinginan untuk mengetahui sesuatu, menghargai fakta dan data, mampu untuk menerima ketidakpastian, instrospeksi kritis, tekun, ulet, tabah, kreatif, berpikir terbuka, dapat bekerjasama dengan orang lain (Haryadi, Djatmiko, \& Setyosari, 2017). Salah satu sikap ilmiah yang seharusnya bisa muncul dalam pembelajaran IPA ialah kretif, kreativitas tidak di tentukan dari materi-materi kurikulum, namun bagaimana seorang guru dapat menciptakan proses pembelajaran di dalam kelas yang dapat merangsang kreativitas siswa, seperti menggunakan model pembelajaran dan media yang tepat agar dapat membuat siswa lebih aktif bertanya, meningkatkan kemampuan sosial dan emosional, menyalurkan ide-ide, serta meningkatkan kreativitas.

Trnova, E (2014) mengemukakan bahwa strategi pembelajaran yang efektif dan dapat berpengaruh terhadap kreativitas adalah kegiatan pembelajaran yang berpusat pada siswa(student centered), dapat menghubungkan antara topik yang diajarkan dengan kehidupan nyata, pengaturan keterampilan dikelas, pertanyaan terbuka, mendorong kemampuan berpikir kreatif dan penggunaan teknologi serta multimedia.Kreativitas juga mempunyai peran penting dalam pendidikan, dan sebagian besar sistem pendidikan mendukung kreativitas sebagai kemampuan yang sangat dibutuhkan di abad21.Kaufman James (2016) mengemukakan bahwa seseorang yang kreatif harus mampu untuk menujukkan sesuatu yang berbeda, menciptakan sesuatu yang baru, atau mampu untuk berinovasi.

Model pembelajaran dan media adalah poin penting yang harus diperhatikan agar pelaksanaan pembelajaran lebih efektif, aktif, dan dapat merangsang kreativitas siswa. Salah satu model pembelajaran yang bersifat student-centered adalah cooperative learning. Pembelajaran kooperatif (cooperative learning) merupakan model pembelajaran dimana beberapa siswa belajar dan mengerjakan sesuatu bersama dalam kelompok kecil beranggotakan empat sampai enam orang dan merupakan kelompok yang heterogen (Rusman 2011: 202).Menurut Slavin (2015), cooperative learning adalah metode pembelajaran dengan cara mengelompokkan siswa secara heterogen, untuk bekerjasama dan saling membantu satu sama lain dalam mencapai suatu tujuan. Salah satu tipe dari model pembelajaran cooperative learning adalah circuit learning. Model pembelajaran circuit learning adalah pembelajaran dengan memaksimalkan peberdayaan pikiran dan perasaan dengan pola bertambah dan mengulang (Dewi, Wiyasa, \& Ganing, 2014). Salah satu kelebihan circuit learning adalah dapat meningkatkan kreativitas siswa dalam menyusun peta pikiran/mind map sendiri dan meningkatkan kemampuan merangkai kata dengan bahasa sendiri (Shoimin Aris, 2014).

Selain model pembelajaran, poin kedua yang sangat mempengaruhi proses pembelajaran adalah media yang digunakan.Penggunaan media pembelajaran dapat membantu guru dalam penyampaian materi, proses pembelajaran lebih aktif karena dapat meningkatkan antusias siswa dan pembelajaran tidak membosankan. Penggunaan media dalam proses belajar mengajar tentunya akan sangat membantu karena dalam sebuah kelas tentunya terdiri dari berbagai macam siswa dan setiap siswa berbeda satu dengan yang lain. Gaya belajar setiap siswa pun berbeda, ada yang belajar dengan melihat (visual), mendengar (auditory), aktif bergerak dan praktik langsung (kinesthetic), dan read/write, sehingga penggunaan media dalam pembelajaran akan sangat membantu siswa dengan berbagai macam gaya belajar.

Terdapat dua jenis media pembelajaran, yaitu multimedia yang menggunakan teknologi tinggi (high technology) dan media sederhana (low technology). Bulut, R (2019) mengemukakan bahwa multimedia dapat didefinisikan sebagai pengaturan digital dimana elemen-elemen dengan karakteristik visual, audio, atau audiovisual yang menarik bagi individu disajikan Copyright C2020, JRPD, ISSN 2615 - 1723 (Print), ISSN 2615 - 1766 (Online) 
dengan cara digabungkan. Dan media sederhana menurut Yaumi (2017) adalah media yang dapat dikembangkan sendiri sesuai dengan kebutuhan melalui pemanfaatan bahan-bahan yang ada dilingkungan sekitar tanpa terhalang biaya yang cukup mahal.

Dari hasil penelitian yang dilakukan oleh Dewi, Wiyasa, Ganing, \& Hum (2014), menyatakan bahwa model circuit learning berbantu media audiovisual berpengaruh terhadap hasil belajar IPS siswa kelas 5, terbukti dari hasil tes kelompok eksperimen yang diperoleh lebih tinggi daripada hasil tes kelompok kontrol. Dan hasil penelitian lain yang dilakukan oleh Wulandari, E (2017) menyatakan bahwa model circuit learning berpengaruh terhadap kemampuan siswa kelas 5dalam mengidentifikasi fungsi organ pernapasan manusia terbukti dari rata-rata hasil tes kelompok eksperimen yang lebih tinggi daripada rata-rata hasil tes kelompok kontrol.

Dari beberapa hasil penelitian diatas, timbul keraguan dan ketertarikan penulis untuk menguji model pembelajaran kooperatif tipe circuit learningyang berbantu multimedia dan yang berbantu media sederhana tidak dilihat dari hasil belajar sajanamundilihat dari aspek kreativitas. Untuk mengetahui pengaruh penerapan model pembelajaran circuit learningyang berbantu multimedia dan yang berbantu media sederhana terhadap kreativitas siswa pada muatan pelajaran IPA. Dan supayaapa yang menjadi tujuan pembelajaran IPA yaitu menumbuhkan sikap ilmiah siswa dan salah satu sikap ilmiah adalah kreatif dapat tercapai.

\section{METODE}

Penelitian ini menggunakan penelitian eksperimen semu (QuasiEksperiment Research). Penelitian eksperimen bertujuan untuk mengetahui pengaruh dari suatu perlakuan tertentu terhadap kelas lain yang sama namundiberikan perlakuan yang berbeda. Penelitian eksperimen dilakukan pada kelas yang akan diberi perlakuan yang disebut kelas eksperimen dan kelas pembanding yang disebut dengan kelas kontrol.
Populasi dan sampel yang dipakai dalam penelitian ini adalah siswa kelas 5 SD Negeri Dukuh 01 Salatiga dengan jumlah siswa 34 siswa dan SD Negeri Kecandran 01 Salatiga dengan jumlah siswa 35 siswa.Alasan pemilihan sampel adalah jumlah siswa yang tidak berbeda jauh dan lokasi penelitian yang masih bisa dijangkau peneliti.

Dalam penelitian ini digunakan beberapa instrumen yang diperlukan, yaitu lembar observasi, soal pretest dan postest, dan rubrik penilaian peta konsep/mind map hasil kreativitas siswa.Lembar instrumen observasi digunakan pada tahap pelaksanaan pembelajaran IPA untuk melihat apakah peneliti benar-benar menggunakan model circuit learning berbantu media, dan juga untuk melihat dampak/pengaruh penerapan model circuit learning berbantu media. Soal pretest dan postest digunakan untuk mengetahui kemampuan siswa sebelum dan sesudah penerapan model circuit learning berbantu multimedia dan media sederhana. Rubrik penilaian hasil peta konsep/mind mapdigunakan untuk mengukur hasil kreativitas siswa yaitu membuat peta konsep/mind map.

Teknik analisis data dilakukan dengan uji normalitas data digunakan agar diketahui data hasil penelitian berdistribusi normal atau tidak. Uji homogenitas tujuan nya untuk mengetahui apakah kedua kelompok mempunyai varian yang homogen atau tidak. Dan uji t untuk mengetahui apakah hipotesis awal diterima atau ditolak.

\section{HASIL DAN PEMBAHASAN}

\section{Pelaksanaan Pembelajaran}

Kelompok eksperimen menggunakan model pembelajaran circuit learning berbantu multimedia pada muatan pelajaran IPA di kelas 5 SD Negeri Dukuh 01 Salatiga, multimedia yang digunakan adalah video. Sedangkan pada kelompok kontrol menggunakan model pembelajaran circuit learning berbantu media sederhana pada muatan pelajaran IPA di kelas 5 SD Negeri Kecandran 01, media sederhana yang digunakan adalah lilin dan air es. Materi Ipa 
Jurnal Riset Pendidikan Dasar, 03 (1), April 2020 (57-63)

Meike Paranna, Gamaliel Septian Airlanda

yang digunakan adalah pengaruh kalor terhadap suhu dan wujud benda. Pada akhir pembelajaran kedua kelompok akan membuat peta konsep/mind map sesuai kreativitas siswa.

\section{Analisis Data Deskriptif}

\section{Kelompok eksperimen}

Kelompok eksperimen menggunakan model pembelajaran circuit learning berbantu multimedia pada muatan pelajaran IPA. Tingkat hasil belajar siswa kelompok ekperimen dipaparkan melalui statistik deskriptif dari hasil pretest dan postest yang terdiri dari rata-rata (mean), nilai tertinggi (max), dan nilai terendah (min), standar deviasi.

Tabel 1. Statistik Deskriptif Nilai Pretest dan Postes

Descriptive Statistics

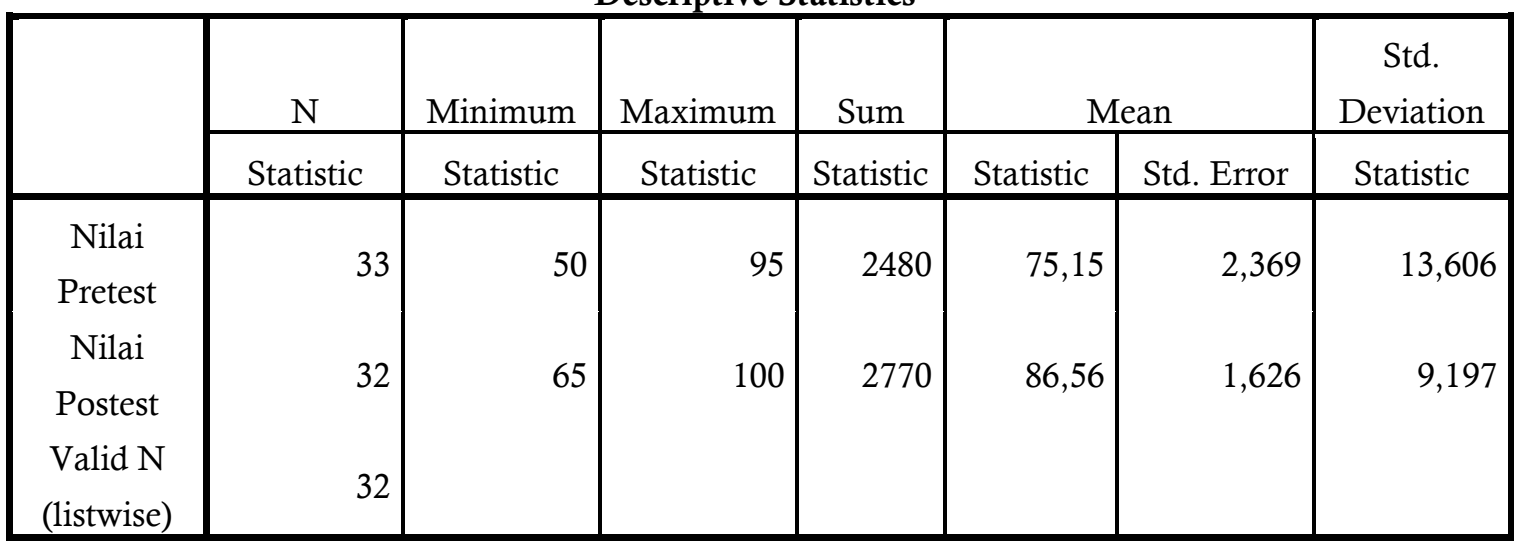

Berdasarkan tabel 1 dapat dilihat bahwa rata-rata(mean) nilai kelompok eksperimen sebelum proses pembelajaran dengan model circuit learning berbantu multimedia (pretest) adalah 75,15 dengan standar deviasi 13,606. Setelah pelaksanaan pembelajaran dengan menerapkan model circuit learning berbantu multimedia didapatkan nilai (postest) meningkat menjadi 86,56 dengan standar deviasi 9,197.Nilai terendah dari pretest kelompok eksperimen adalah 50 dan nilai tertinggi 95 . Nilai terendah postest adalah 65 dan nilai tertinggi 100.

Tabel 2. Statistik Deskriptif Nilai Pretest dan Postest

Descriptive Statistics

\begin{tabular}{|c|c|c|c|c|c|c|c|}
\hline & $\mathrm{N}$ & Minimum & Maximum & Sum & \multicolumn{2}{|c|}{ Mean } & $\begin{array}{c}\text { Std. } \\
\text { Deviation }\end{array}$ \\
\hline & Statistic & Statistic & Statistic & Statistic & Statistic & Std. Error & Statistic \\
\hline $\begin{array}{c}\text { Nilai } \\
\text { Pretest }\end{array}$ & 33 & 45 & 90 & 2270 & 68,79 & 2,018 & 11,594 \\
\hline $\begin{array}{c}\text { Nilai } \\
\text { Postest } \\
\text { Valid N } \\
\text { (listwise) }\end{array}$ & $\begin{array}{l}32 \\
32\end{array}$ & 65 & 100 & 2615 & 81,72 & 1,581 & 8,945 \\
\hline
\end{tabular}

Copyright (C2020, JRPD, ISSN 2615 - 1723 (Print), ISSN 2615 - 1766 (Online) 


\section{Jurnal Riset Pendidikan Dasar, 03 (1), April 2020 (57-63) \\ Meike Paranna, Gamaliel Septian Airlanda}

Berdasarkan tabel 2 dapat dilihat bahwa rata-rata(mean) nilai kelompok kontrol sebelum proses pembelajaran dengan model circuit learning berbantu media sederhana(pretest) adalah 68,79 dengan standar deviasi 11,594.Setelah pelaksanaan pembelajaran dengan menerapkan model circuit learning berbantu media sederhana didapatkan mean nilai (postest) meningkat menjadi 81,72 dengan standar deviasi 8,945. Nilai terendah dari pretest kelompok kontrol adalah 45 dan nilai tertinggi 90 . Nilai terendah postest adalah 65 dan nilai tertinggi 100 .

\section{Deskripsi Komparasi Hasil Pengukuran}

Deskripsi komparasi dalam penelitian ini memaparkan perbandingan hasil pengukuran kelompok eksperimen dan kelompok kontrol berdasarkan nilai pretest dan postest. Deskripsi komparasi disediakan dalam bentuk Tabel 3 dan Gambar 1.

Tabel 3 Komparasi Hasil Pengukuran Kelompok Eksperimen dan Kontrol

\begin{tabular}{llll}
\hline \multirow{2}{*}{ Pengukuran } & \multicolumn{2}{l}{ Rerata skor kelompok } & $\begin{array}{c}\text { Selisih } \\
\text { Eksperimen }\end{array}$ \\
\cline { 2 - 3 } Pretest & 15,03 & 13,75 & 1,28 \\
Postest & 17,31 & 16,34 & 0,97 \\
\hline
\end{tabular}

Sumber Data Primer

Dari tabel 3 menunjukkan komparasi hasil pengukuran terdapat perbedaan rata-rata skor perolehan pretest antara kelompok eksperimen dan kelompok kontrol dengan selisih 1,28 . Sedangkan perbedaan rata-rata postest antara kelompok eksperimen dan kelompok kontrol adalah 0,97. Secara singkat deskripsi komparasi hasil pengukuran dapat dilihat pada Gambar 1.

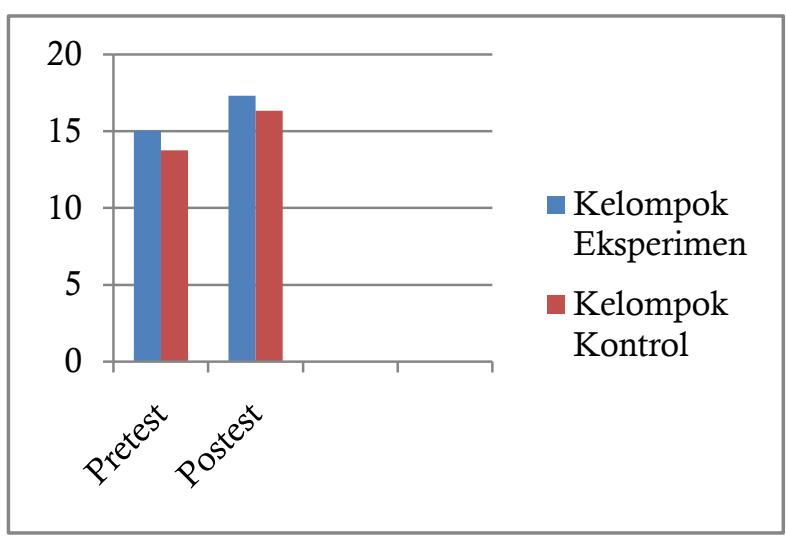

Gambar 1. Diagram Komparasi Hasil Pengukuran Kelompok Eksperimen dan Kontrol

Dari gambar 1 dapat dilihat rata-rata nilai hasil pretest kelompok eksperimen sebesar 15,03 dan setelah penerapan model circuit learning berbantu multimedia, hasil postest kelompok eksperimen menjadi 17,31 . Rata-rata nilai hasil pretest kelompok kontrol adalah 13,75, dan setelah penerapan model circuit learning berbantu media sederhana, nilai postest menjadi 16,34.

\section{Hasil Pengukuran Kreativitas}

Setelah pembelajaran IPA menggunakan model pembelajaran circuit learning, siswa membuat peta konsep/mind map dalam kelompok sesuai kreativitas siswa. Berikut tabel hasil penilaian kreativitas siswa membuat peta konsep/mind map.

Tabel 4 Hasil Penilaian Kreativitas Siswa Membuat Peta Konsep

\begin{tabular}{ccc}
\hline No & \multicolumn{1}{c}{ Kelompok } & $\begin{array}{c}\text { Rata-rata } \\
\text { Nilai }\end{array}$ \\
1. & Kelompok Eksperimen & 3,38 \\
2. & Kelompok Kontrol & 2,94 \\
\hline
\end{tabular}

Sumber Data Primer

Dari tabel 4 dapat dilihat bahwa hasil rata-rata penilaian kreativitas siswa pada kelompok eksperimen yang menggunakan model circuit learning berbantu multimedia mempunyai

Copyright C2020, JRPD, ISSN 2615 - 1723 (Print), ISSN 2615 - 1766 (Online) 


\section{Jurnal Riset Pendidikan Dasar, 03 (1), April 2020 (57-63)}

Meike Paranna, Gamaliel Septian Airlanda

rata-rata 3,38 dari rata-rata skor maksimal 4,00 sedangkan pada kelompok kontrol yang menggunakan model circuit learning berbantu media sederhana mempunyai rata-rata 2,94 dari rata-rata skor maksimal 4,00.

\section{Analisis Data Inferensial}

Uji normalitas bertujuan untuk mengetahui apakah data pada kelompok kontrol dan eksperimen berdistribusi tidak normal atau normal. Berdasarkan hasil uji normalitas hasil pretest dan postest. Didapatkan hasil uji normalitas dua sisi dengan taraf kepecayaan 95\% (Asyimp. Sig.2-tailed). $\mathrm{H}_{0}$ diterima apabila probabilitas > 0.05 dan $\mathrm{H}_{\mathrm{a}}$ ditolak. Sedangkan, jika probabilitas $<0,05 \mathrm{H}_{\mathrm{a}}$ diterima dan $\mathrm{H}_{0}$ ditolak. Hasil uji normalitas sebagai berikut.

1. Tingkat signifikasi nilai pretest kelompok eksperimen adalah $0.155>0,05$, artinya nilai berdistribusi normal.

2. Tingkat signifikasi nilai postest kelompok eksperimen adalah $0,088>0,05$, artinya nilai berdistribusi normal.

3. Tingkat signifikasi nilai pretest kelompok kontrol adalah $0,84>0,05$, artinya nilai berdistribusi normal.

4. Tingakt signifikasi nilai postest kelompok kontrol adalah $0,079>0,05$, artinya nilai berdistribusi normal.

Uji homogenitas dilakukan untuk melihat apakah sampel kelompok kontrol dan kelompok eksperimen homogen/memiliki varian yang sama atau tidak. Dapat dikatakan homogen apabila nilai signifikasi $>0,05$ dan dikatakan tidak homogen apabila nilai signifikasi < 0,05.Dari hasil uji homogenitas Test of Homogenity of Variances dengan metode Levene's Test, menunjukkan bahwa nilai signifikasi uji homogenitas pretest adalah 0,437 > 0,05 sehingga dikatakan homogen, dan hasil uji homogenitas postest nilai signifikasi adalah $0,976>0,05$ sehingga dapat dikatakan bahwa varian kelompok eksperimen dan kelompok kontrol memiliki varian yang sama.
Uji $\mathrm{T}$ bertujuan untuk mengetahui ada tidaknya perbedaan pengaruh antara kelompok eksperimen dan kelompok kontrol terhadap kreativitas siswa. Perhitungan uji $\mathrm{t}$ dilakukan dengan bantuan IBM SPSS STATISTIC 23 menggunakan Independent Sample Test. Berdasarkan hasil uji t menggunakan independent samples test, nilai $t_{\text {hitung }}$ sebesar 2,393 dengan nilai signifikasi (2-tailed) sebesar $0,020<0,05$. Hipotesis awal dalam penelitian ini adalah $\mathrm{H}_{\mathrm{o}}$ : Model pembelajaran circuit learning berbantu media sederhana lebih berpengaruh terhadap kreativitas siswa muatan pelajaran IPA, dan perlu dibuktikan melalui teknik analisis uji t.

Uji hipotesis adalah proses pengambilan keputusan dimana peneliti memberikan penilaian hasil penelitian terhadap hipotesis awal mereka(Gay,Mills, \&Airasian, 2012).Berdasarkan hasil kriteria pengujian hipotesis menggunakan independent sample t-test menunjukkan bahwa nilai signifikasinya adalah $0,020<0,05$ sehingga $\mathrm{H}_{0}$ ditolak dan $\mathrm{H}_{\mathrm{a}}$ diterima. Hipotesis akhir $\left(\mathrm{H}_{\mathrm{a}}\right)$ dalam penelitian ini adalah model pembelajaran circuit learning berbantu multimedia lebih berpengaruh terhadap kreativitas siswa.Dapat disimpulkan bahwa model pembelajaran circuit learning berbantu multimedia lebih berpengaruh terhadap kreativitas siswa. Keberhasilan penelitian ini di dukung dengan adanya peningkatan hasil pretest ke postest dan juga ratarata hasil penilaian kreativitas siswa yaitu membuat peta konsep/mind map yang lebih tinggi dibandingkan dengan menggunakan model pembelajaran circuit learning berbantu media sederhana.

Perubahan hasil dari pretest ke postest menunjukkan model pembelajaran circuit learning berbantu media dapat berpengaruh terhadap hasil belajar siswa. Hasil ini mendukung hasil penelitian yang telah dilakukan oleh Wulandari (2017) yang menyatakan bahwa model circuit learning berpengaruh terhadap kemampuan siswa kelas 5 dalam muatan pelajaran IPA, materi mengidentifikasi fungsi organ pernapasan.Dari hasil penilaian kreativitas siswa juga mendukung Copyright (C2020, JRPD, ISSN 2615 - 1723 (Print), ISSN 2615 - 1766 (Online) 


\section{Jurnal Riset Pendidikan Dasar, 03 (1), April 2020 (57-63)}

Meike Paranna, Gamaliel Septian Airlanda

teori Shoimin Aris (2014) yang menyatakan bahwa circuit learningdapat meningkatkan kreativitas siswa dalam menyusun peta pikiransendiri dan meningkatkan kemampuan siswa dalam merangkai kata dengan bahasa sendiri

Selain berpengaruh terhadap kreativitas, penggunaan model circuit learning berbantu multimedia dapat meningkatkan motivasi belajar siswa, dapat menjangkau semua gaya belajar, dapat membuat proses pembelajaran lebih menarik, interaktif, melatih kepercayaan diri siswa, dan melatih siswa untuk mampu bekerjasama dalam tim/kelompok. Hal-hal ini dilihat langsung oleh peneliti saat melakukan observasi selama penelitian.

\section{DAFTAR PUSTAKA}

Bulut, R. (2019). An Analysis Of The Effects Of Multimedia Teaching On Student Achievement. International Journal of Progressive Education, 15(1).

Dewi, D. A. P., Wiyasa, I. K. N., Kes, M., Ganing, N. N., \& Hum, M. (2014). Pengaruh Model Pembelajaran Circuit Learning Berbantuan Media Audiovisual Terhadap Hasil Belajar Ips Siswa Sd Negeri 1 Pejeng Tahun Pelajaran 2013/2014. Mimbar Pgsd Undiksha, 2(1). Retrieved from https://ejournal.undiksha.ac.id/index.php /JJPGSD/article/view/2226

Gay, L. R., Mills, G. E., Airasian, P. W. 2012. Educational Research: Competencies For Analysis and Applications. Boston: Pearson.

Haryadi, S., Djatmika, E. T., \& Setyosari, P. (2017, June). Pembelajaran Tematik Dalam Menumbuhkan Sikap Ilmiah Dan Keterampilan Berpikir Kritis Siswa Sd. In Prosiding Seminar Nasional Mahasiswa Kerjasama Direktorat Jenderal Guru Dan Tenaga Kependidikan Kemendikbud 2016. Retrieved from http://pasca.um.ac.id/conferences/index. $\mathrm{php} / \mathrm{gtk} / \mathrm{article} / \mathrm{view} / 282$

Kaufman, J. C. (2016). Creativity 101. Springer Publishing Company.
Rusman. 2011. Model-Model Pembelajaran: Mengembangkan Profesionalisme Guru. Jakarta: Raja Grafindo Persada.

Shoimin, Aris. 2014. 68 Model Pembelajaran Inovatif Dalam Kurikulum 2013. Yogyakarta: Ar-Ruzz Media.

Slavin, R. E. (2015). Cooperative Learning In Elementary Schools. Education 3-13, 43(1), 5-14.

Trnova, E. (2014). Ibse And Creativity Development. Science Education International, 25(1), 8-18. Retrieved from https://eric.ed.gov/?id=EJ1022897

Wulandari, E. D. (2017). The Effect Of Circuit Learning Model Which Supported Realia Media For The Ability To Identity Of Respiratory Organ Function For V Grade Student Burengan Pesantren Districts Kediri City Academic Year 2016/2017.

Yaumi, Muhammad. (2017). Ragam Media Pembelajaran: Dari Pemanfaatan Media Sederhana Ke Penggunaan Multi Media.

Copyright C2020, JRPD, ISSN 2615 - 1723 (Print), ISSN 2615 - 1766 (Online) 